\title{
THE ROLE OF HORTICULTURE IN THE GLOBAL STRATEGY FOR PLANT CONSERVATION
}

\author{
DAVID RAE*
}

The Global Strategy for Plant Conservation contains 16 targets for plant conservation to be met by the year 2010. All 16 are applicable to the work of botanic gardens and at least 8 are relevant to the type of horticulture that is practiced in botanic gardens. This paper argues that the skills of botanical horticulturists are needed if the GSPC is to be successful. It encourages horticulturists in botanic gardens to join with other scientists and practitioners in helping to realise the potential of the GSPC to make a real impact in plant conservation.

\section{INTRODUCTION}

This article is based on papers given at a PlantNet conference held at Reading University in early January 2004 (Implementing the Global Strategy for Plant Conservation) and at the World Botanic Gardens Congress in Barcelona in April 2004. At the Royal Botanic Garden Edinburgh (RBGE), 'the five Cs' have been coined as an idea or phrase to describe succinctly what botanic gardens do - they stand for Classify, Cultivate, Conserve, Curate and Communicate. These activities encapsulate the work of typical botanic gardens and, cross-checked against the Global Strategy for Plant Conservation (GSPC), show that the work undertaken in botanic gardens is highly relevant to delivering the targets contained in the Strategy. The purpose of the lectures in Reading and Barcelona was to demonstrate that the horticultural work that takes place in botanic gardens has a very real and important role to play in contributing to the GSPC.

Horticulture could contribute to 14 of the 16 targets but, realistically, there are eight in which botanic garden horticulture can genuinely make a valuable contribution. All targets are planned to be achieved by 2010 . This date has been set to synchronise the Strategy with the Convention on Biological Diversity (CBD) Strategic Plan.

\section{TARGET 1}

Target 1 calls for a widely accessible working list of known plant species as a step towards a complete world flora. Ex situ live plant collections in botanic gardens have traditionally been used to support taxonomic research and, while horticulture's contribution in this area will not make an immediate impact allowing the target suddenly to be met by 2010 , nonetheless the continual background support to taxonomic research by horticulture in botanic gardens is of significant value.

The sorts of work or actions that horticulture can provide to help this type of research include cultivating plants until they flower and/or set seed, flower initiation

\footnotetext{
" David Rae is Director of Horticulture at the Royal Botanic Garden Edinburgh Address: Royal Botanic Garden Edinburgh, 20a Inverleith Row, Edinburgh, EH3 5LR

Email: d.rae@rbge.org.uk
} 
trials, the cultivation of plants that are difficult to press such as orchids or succulents and the cultivation of a wide range of well grown plants as aids to taxonomic description. To improve upon and increase this capability, the following are required:

- More trained botanic garden horticulturists

- Good, modern growing facilities in more botanic gardens

- The ability of staff to cultivate a wide range of plants from seed to flowering (as all stages of development might be of importance in taxonomic descriptions or for observation)

- An understanding of the importance of plant records and of other documentation.

\section{TARGET 3}

Target 3 reads as follows: Development of models with protocols for plant conservation and sustainable use, based on research and practical experience. This target is looking for good examples of integrated conservation to act as models and examples of best practice that others can adopt or reshape to their own needs and then apply. It is particularly good because it recognises the need for research and practical experience. In so doing it emphasises the importance of horticultural practice in delivering conservation success on the ground and offers horticulturists the opportunity to become involved. Good examples of this approach at RBGE have been the reintroduction of Lychnis viscaria and Woodsia ilvensis (Lusby et al, 2003), both of which have had a sound scientific base but have also relied heavily on practical horticultural skills. In this respect the horticultural aspects of re-introduction programmes should not be underestimated.

The International Conifer Conservation Programme, based at RBGE (Gardner, 2003), is also an excellent example, bringing together in situ and ex situ conservation, high quality research, a 'safe site' programme, practical horticulture and training (in both horticulture and taxonomy) into a co-ordinated package of activities.

\section{TARGET 7}

Target 7 states that $60 \%$ of the world's threatened species should be conserved in situ. Some might think that this was a target that would not involve horticulture but they would be wrong. The detrimental pressures on the world's habitats are so strong that even so-called wilderness areas or national parks have to be managed or manipulated to some extent. Thus, in situ conservation often involves horticultural intervention and the importance of horticultural techniques in 'helping' struggling species should not be underestimated. This point is described in more detail in the paper All the world's a garden (Blackmore, 2001). Clearing the encroachment of scrub over limestone pavements, fencing to prevent grazing, pond clearing, the removal of invasive aliens, diversion of visitors from sensitive areas and the removal of competition by spot spraying or physical removal are all techniques that are used in in situ conservation to protect individual species and are all basically horticultural in nature. 


\section{TARGET 8}

Target 8 states that $60 \%$ of threatened plant species are to be in ex situ collections, preferably in the country of origin, and $10 \%$ of them included in recovery and restoration programmes. This is perhaps the most obvious place where botanic garden horticulturists can see where they fit into the GSPC. However, to reach this target botanic gardens need to be efficient and effective in the cultivation of threatened plants which can often be challenging. We therefore need good, trained botanical horticulturists as mentioned before working in good, modern facilities. If the plants are to be grown 'preferably in the country of origin' then a more appropriate distribution of botanic gardens across the globe is required, especially in Africa, South America and parts of Asia. Training, development and capacity building in countries where there are few, new or poorly developed botanic gardens is therefore very important but is dealt with later, in Target 15.

However, to effectively grow $60 \%$ of a country's threatened plants requires more than skilled staff and good facilities. It requires a good deal of knowledge about what is in cultivation and what others are growing. It also requires communication and coordination between botanic gardens to ensure that all target specimens are included and no gaps are left. The recently launched BGCI website (www.bgci.org.uk) has a very important role to play here in allowing staff to find out how many other gardens are growing certain plants.

A recently launched PlantNet (the plant collection network of Britain and Ireland) project is worth noting in this context. The plan is to use the network of member gardens (over 100) to grow genetically structured (as far as possible) conservation collections of British and Irish Red Book-listed specimens. Each participating garden will take on around two to three species of threatened plant in their region. In this way the full range of microclimates found across Britain and Ireland can be put to use in growing the diversity of species concerned. Duplication will be reduced to a minimum and, hopefully, gaps will be eliminated. With only two to three species to look after, it is hoped that participating gardens will be asked to grow several individuals from each of the populations found in Britain and Ireland as opposed to the current situation where most gardens have one to two individuals of a few species. It is hoped that this project will provide a model that could be adopted elsewhere.

\section{TARGET 10}

Invasive alien species have caused massive loss of habitat and many countries, especially fragile island ecosystems, are starting to generate the will to begin tackling the issues. Evidence of this can be seen in the fact that invasive aliens are rising up the ecological and political ladder. The European Union, for instance, is beginning to take the issues posed by these plants seriously and is planning to bring in legislation intended to start controlling the spread of these plants.

The control of alien invasive species usually involves horticultural techniques such as spraying or physical removal. Most of this work, however, is usually undertaken by contractors or local authorities rather than botanic gardens although botanic gardens are often asked for help in identifying the species or recommending control measures. 
The pertinent issue here for horticulture is perhaps not control, but rather the responsibility not to allow potentially invasive alien species to enter or escape from our gardens. Vigilance is required to identify potentially invasive species and to check the areas around boundaries to ensure nothing is escaping. This is particularly the case for botanic gardens in rural areas or bounded by wilderness areas or nature reserves.

\section{TARget 14}

Target 14 is about the importance of communication. It states that the importance of plant diversity and the need for its conservation should be incorporated into communication, education and public-awareness programmes.

Most botanic gardens now have professional education staff whose primary responsibility is to communicate with the public. However, horticultural staff are frequently good communicators and it should not always be left to education staff to speak to students or visitors. The public often like to hear directly from people with real experience, and what some horticultural staff might lack in professional communication skills they often more than compensate for in their 'real life' knowledge of plant cultivation. Simple live demonstrations of processes or techniques that might seem incredibly ordinary or mediocre to many horticultural staff can often be more interesting than might have been imagined to the lay public or students.

\section{TARget 15}

Target 15 comes within the section on building capacity for the conservation of plant diversity. It says that the number of trained people working with appropriate facilities in plant conservation should be increased, according to national needs, to achieve the targets of this Strategy. This refers to all types of staff involved in plant conservation but within the boundaries of this paper it refers to horticulturists who, as this paper is arguing, have an important role to play in the GSPC. There is a great need for skilled botanical horticulturists in biodiversity-rich developing countries, and staff in developed country botanic gardens can play a valuable part in providing this training. Topics such as cultivation, propagation and plant records are all necessary and often are best taught as on-the-job training rather than in the classroom.

Staff exchanges are a helpful and practical way of achieving this. Staff from developed countries can travel to gardens seeking help in this area and can provide demonstrations, workshops and hands-on work. In this way there is also a benefit to the gardens sending staff, because the staff involved get the chance to travel, see new botanic gardens and, probably, plants growing in the wild which can help them in their work back home. Working the other way, if funds can be found, selected staff from developing countries can travel to botanic gardens in developed countries for training. Even intense, short periods of three to four weeks can help a lot, although longer periods are obviously better.

The Darwin Initiative project running in Bhutan, based at RBGE, takes part in exactly the type of exchanges described above. Two staff from Edinburgh travel to Bhutan each year, for three years, to give demonstrations, workshops and to work shoulder to shoulder on the ground with staff from RBG Serbitang in Bhutan. Two staff from Serbitang then travel to Edinburgh each year for the three years of the project for practical training. While the project is primarily aimed at helping RBG 
Serbitang, the benefit is certainly not only one way as staff from Edinburgh have enjoyed and benefited from the experience too.

While giving help to others is the primary purpose of the target, it should not be forgotten that standards of horticulture in our own botanic gardens are important too and that we have a duty to keep striving for better trained staff - which can only be achieved through continuous training. With so many legislative issues requiring training, it is easy to forget that horticultural training requires input too and all botanic gardens have a duty to ensure that staff receive on-going horticultural training through on-the-job supervision, in-house training sessions or training days, through bought in help or attendance at external courses.

\section{TARget 16}

Target 16 calls for networks for plant conservation activities to be established or strengthened at national, regional and international levels. Networks provide an excellent forum for staff to get together to share ideas, techniques and problems. They can also create a focus for activity and allow regional, joint projects to take place. Networks operate and are administered in many different ways and offer many different activities including conferences, special interest focal groups, visits, workshops and, sometimes, specialist training. Through these activities and the production of publications such as strategies and guidelines for activities or projects, they are able to raise standards. Many networks have been created in recent years and now operate at country, regional and global levels. As a result, communication between staff in botanic gardens, including horticulturists who have often been slow to network, has never been better.

As well as raising standards and communicating within botanic gardens, networks create the opportunity to be outward-looking, to engage with others involved in conservation and to join in with integrated activities. For many years botanic gardens appeared to be inward-looking and seldom integrated with other conservation agencies. This is no longer the case - botanic gardens are now deeply involved with a wide range of compatible organisations and horticulturists have a real chance to get involved here, to understand the work that others are doing and to offer their horticultural knowledge and solutions to others.

\section{NEXT STEPS}

Horticultural staff in botanic gardens need to become fully informed about the GSPC and discuss how they can contribute. The following points can provide a checklist of possible actions:

- Make sure that horticultural staff know about the GSPC, for instance by holding a staff meeting to describe the targets contained in the Strategy

- Make the point that horticulture has a useful role to play by giving examples of projects or practices

- Hold a staff meeting to discuss what could be done

- Concentrate on projects that can be done well and will achieve a genuine output 
- Analyse your collection to see what else you could be growing and what might be appropriate to reintroduce locally or further afield

- Don't act in isolation but collaborate where possible and check what others are doing

- Think about how you can contribute to training and capacity building both at home and in biodiversity-rich countries

- If possible act locally, nationally and internationally through established networks

\section{SUMMARY OF THE HORTICULTURAL CONTRIBUTION TO THE GSPC}

The following points provide a summary of the activities that horticultural work in botanic gardens can contribute to the GSPC.

- Support taxonomy by good cultivation

- Ensure the horticultural contribution to integrated conservation is appreciated

- In situ conservation often needs horticultural skills

- Make ex situ collections as efficient and effective as possible

- Encourage horticultural staff to get involved in education and don't neglect the value of horticultural practices and procedures

- Encourage/take part in staff exchanges as a practical and effective way of improving training and capacity building

- Contribute to training and capacity building at all levels by taking part in botanic garden networks

\section{REFERENCES}

BLACKMORE, STEPHEN (2001). All the world's a garden. The Horticulturist. 10:1. 13-16

LUSBY, PHILIP, DYER, ADRIAN AND LINDSAY, STUART (2003). The role of botanic gardens in species recovery: the Oblong Woodsia as a case study. Sibbaldia: An occasional series of horticultural notes from the Royal Botanic Garden Edinburgh. 1, 5-10

GARDNER, M. (2003). The international Conifer Conservation Programme. Proceedings of the Fourth International Conifer Conference (Wye College, 1999). Acta Horticulturae 615. Leuven, Belgium, International Society for Horticultural Science 